\title{
Balnearios en la Gran Canaria, cualquier tiempo pasado fue, en este caso, ;mejor!
}

\author{
Spas in Gran Canaria, any past was, in this case, better! \\ Jiménez Díaz $\mathrm{JF}^{(1)}$, Rodríguez de Vera $\mathrm{BC}^{(1)}$, Jiménez Rodríguez $\mathrm{C}^{(1)}$, \\ Hernández Martínez FJ ${ }^{(1)}$, Jiménez Rodriguez $\mathrm{Y}^{(2)}$ \\ ${ }^{(1)}$ Grupo I+D+i “Cipronal” Universidad de Las Palmas de Gran Canaria \\ ${ }^{(2)}$ Instituto-Museo Canario del Agua \\ jjimenez@denf.ulpgc.es
}

\section{Resumen}

La isla de Gran Canaria, por su naturaleza volcánica, ha propiciado el alumbramiento de manantiales de aguas termales. Debido a las coladas volcánicas y a la composición geológica de sus diversos estratos, ricos en hierro, silicatos, gas carbónico, etc., se confirió a muchas de sus aguas nacientes propiedades mineromedicinales. Esta condición facilitó su aprovechamiento como elemento terapéutico al tiempo que se inició en el territorio insular el turismo balneario, siguiendo la corriente imperante en Europa durante el siglo XIX. Así, en 1868 se construyó el Balneario de Azuaje generando, así mismo, una oferta alojativa de fondas y hoteles en los municipios de Firgas y Moya, limítrofes en la cuenca suministradora de dicho bien natural. Otros balnearios, y sus correspondientes infraestructuras hoteleras, fueron incorporándose a lo largo de dicha centuria y de la siguiente para generar, en un territorio tan limitado como el que representa la superficie de Gran Canaria, una verdadera isla saludable. No en balde, la Guía de Balnearios de 1947 cita seis balnearios activos en esa fecha: Los Berrazales, Cristo del Rincón, Firgas, Santa Catalina, San Roque y Teror. Desgraciadamente, el balneario emblemático de Azuaje se cerró en 1938 por razones sanitarias, y la enorme riada de 1955 terminó por destrozar la mínima infraestructura existente de los baños. Sin embargo, nuevos nichos de negocio en la segunda mitad del siglo XX reorientaron las bondades salutíferas de las aguas mineromedicinales de Gran Canaria hacia la explotación de envasado y comercialización embotellada de las mismas. No obstante, en la actualidad, de los manantiales que recogía la Guía de Balnearios de 1947 no pervive ninguno $\mathrm{y}$, de esa segunda actividad de explotación mencionada solamente se aprovechan las aguas de Firgas y las aguas de Teror. En los últimos años, el Cabildo Insular de Gran Canaria, a través de su departamento de Cultura y Patrimonio Histórico ha realizado una excelente labor de catalogación de los bienes balnearios 
inventariables. Sin embargo, al figurar dichos recursos naturales como propiedad privada ha limitado el acondicionamiento de los mismos y, por otra parte, al estar todos ellos enmarcados en parajes de protección natural y paisajística, ha incrementado los obstáculos legales para su rehabilitación y puesta en explotación. Sería deseable que la institución insular siguiera impulsando la protección legal de dichos bienes y recursos naturales como Bienes de Interés Cultural y de cualquier otra figura que contemple el ordenamiento jurídico, al tiempo que se facilitara su explotación y se recuperara la riqueza de salud y de turismo aparejada a los mismos mediante programas y campañas de publicidad que permitiera incorporar al eslogan que habitualmente define a nuestra isla, "continente en miniatura", el que nos definió en la segunda mitad del siglo XIX como "isla saludable", al albur de las corrientes que también imperan en la actualidad en la industria turística. No en balde, ya Gregorio Marañón abogaba en 1931 por la "necesaria resurrección de los balnearios españoles".

Palabras clave: Balnearios, Gran Canaria, Turismo, Salud

Key words: Spa, Gran Canaria, Tourism, Health

\section{Referencias}

Instituto Geológico y Minero de España. Manantiales minero-medicinales de España. Madrid, 1947.

Fedac. Fundación para la Etnografía y el desarrollo de la Artesanía Canaria. Carta Etnográfica de Gran Canaria, 2012.

Patronato de Turismo de Gran Canaria. Gran Canaria Spa, Wellness \& Health, 2012.

Marañón G. Dominio, balneario y aguas de La Isabela: sobre la necesaria resurrección de los balnearios españoles. Madrid, 1931. 